\title{
Indústrias criativas - mídia, cultura, economia e criatividade
}

\author{
Creative industries - media, culture, economy and creativity \\ Industrias creativas - media, cultura, economía y creatividad
}

DOI: $10.1590 / 1809-58442017312$

\section{João Paulo Faustino}

(Universidade do Porto, Faculdade de Letras, Departamento de Ciências da Comunicação e da Informação. Porto, Portugal)

\section{Entrevista concedida a}

\section{Sonia Virginia Moreira}

(Universidade do Estado do Rio de Janeiro, Faculdade de Comunicação Social, Programa de Pós-Graduação em Comunicação Social. Rio de Janeiro - RJ, Brasil)

As singularidades das indústrias criativas justificam algumas abordagens do ponto de vista da organização e da gestão. No âmbito específico da indústria de comunicação,

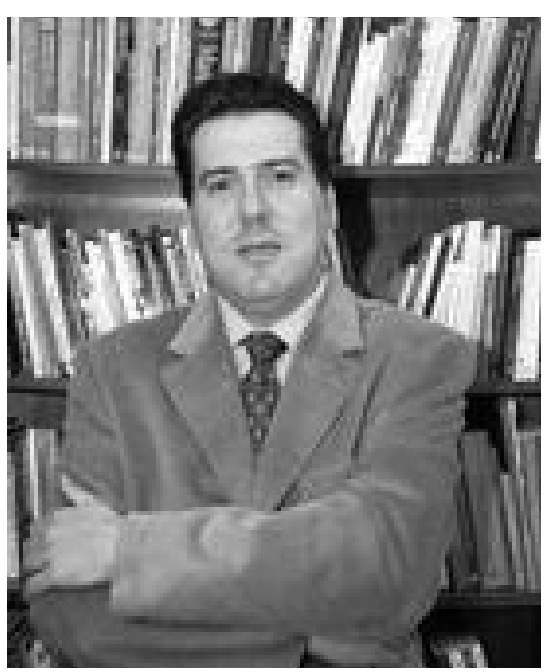
muitos estudos têm por objetivo compreender e encontrar modelos e teorias que permitam conciliar e legitimar princípios econômicos de gestão adaptados e contextualizados. O interesse pelo estudo e aplicação dos princípios econômicos na indústria de comunicação tem crescido na sequência da conjugação de diversos fatores, dentre eles, um em especial: a emergência de forças tecnológicas, reguladoras, sociais e globais que hoje afetam as empresas de um modo geral (públicas ou privadas) e suas funções como instituições.

Essas e outras questões são abordadas aqui pelo investigador português João Paulo Faustino, pesquisador do CIC.Digital - Centro de Investigação em Informação, Comunicação e Cultura Digital na Universidade Nova de Lisboa, com pós-doutorado pela mesma universidade, e sócio fundador da editora Media XXI. Seu interesse, ao estabelecer conexões entre as áreas de economia e administração em pontos de interseção com a comunicação, é equacionar economia, gestão, mercado e políticas públicas de mídia. Sua produção inclui livros sobre gestão e empreendedorismo de mídia e artigos sobre concentração de mídia, indústria de conteúdo, indústria criativa. Nesta entrevista, João 
Paulo Faustino trata das origens das indústrias criativas e de como a comunicação se situa nesse ambiente, de questões que envolvem jornalismo e tecnologias e da relevância de um espaço plural para a mídia na consolidação da democracia.

Revista Intercom - Alguns acadêmicos brasileiros da área de Comunicação, pesquisadores proeminentes do campo e referências em seus respectivos campos, enxergam com alguma desconfiança os estudos que alcançam a área de administração, identificada tão somente como de marketing e administração de empresas. Essa resistência talvez explique a relativamente baixa produção sobre o tema e também a ausência de disciplinas que tratem da gestão em meios privados e públicos na formação dos alunos de Jornalismo, por exemplo. Por que o estudo da administração importa ao campo da Comunicação?

João Paulo Faustino - Primeiro importa referir que o produto jornalístico constitui apenas uma das partes mais visíveis do trabalho e da contribuição de vários profisionais que não são apenas jornalistas, estão também em organizações formais ou informais, pequenas ou grandes, públicas ou privadas, profissionais ou amadoras, que recorrem a diversos tipos de saberes para criar e disseminar um conteúdo - informativo, lúdico ou de outra natureza. Neste sentido, as empresas de mídia e de entretenimento converteram-se em referência da atividade empresarial por serem elas próprias atividade fundamental também nos setores político e social. Essas empresas estão inseridas em um ambiente cada vez mais concorrencial e com modelos de negócio diversos e complexos. Além dessas dinâmicas, é preciso realçar as características que condicionam a gestão das atividades empresariais ligadas à informação, à comunicação e ao entretenimento quanto às especificidades dos produtos midiáticos, assim como o trabalho profissional e intelectual intensivo que determina o valor agregado à atividade. As empresas jornalísticas são organizações inseridas em contexto de mercado com especificidades concretas - como a função cultural, educativa e seu impacto na formação dos cidadãos. Enquanto tais, necessitam de competências de organização e gestão, incluindo a criação de conteúdos, para conseguirem otimizar os recursos materiais e humanos que são sempre bens escassos. Assim se justifica a investigação das competências de gestão aplicadas às indústrias de mídia e criativas. Mesmo que uma organização de mídia não tenha atividade orientada para o mercado, ela precisa saber gerir os seus recursos.

Revista Intercom - A designação 'indústria criativa'é recente. Tem sido um tema recorrente de livros, artigos e de encontros nacionais e internacionais que tratam da comunicação, como é o caso das conferências anuais da IMMAA (International Media Management Academic Association), que você preside atualmente. Quais são as pertinências dessa área e como ela se molda a economias e culturas nos diferentes países?

Faustino - É possível localizar a origem do campo nos primeiros relatórios do Departamento de Cultura, Mídia e Esporte do Reino Unido (Creative Industries Mapping Documents, 
1998) e da Conferência das Nações Unidas sobre Comércio e Desenvolvimento (Creative Economy Report. The Challenge of Assessing the Creative Economy Toward Informed Policy Making, 2008). Ambos concluíram que as indústrias culturais representavam uma parte relativamente marginal das chamadas indústrias criativas, quer em termos de mapeamento, quer em termos de volume de negócios. Apesar de o Reino Unido estar na linha de frente da discussão e do desenvolvimento de políticas públicas orientadas para o setor criativo e cultural, o conceito (o campo de estudo) começou a ser elaborado no início da década de 1990 na Austrália no contexto de uma proposta radical para a reforma das artes e das políticas culturais e dos respectivos mecanismos de financiamento, com um papel ativo desempenhado por universidades como a Queensland University. Na União Europeia, os estudos sobre o significado econômico e social do setor cultural começaram por iniciativa do governo Tony Blair (1997-2007), quando se concluiu que atividades da economia criativa correspondiam a 3,8\% dos empregos e a 4,5\% do Produto Interno Bruto - hoje chega a representar entre $5 \%$ e $6 \%$ do PIB da Grã-Bretanha, maior do que a indústria automobilística. É igualmente um setor que apresenta uma das taxas mais expressivas em termos de impactos diretos ou indiretos no turismo, em especial no que diz respeito ao patrimônio cultural e a atividades de lazer. O reconhecimento da importância desta indústria, por parte da União Europeia, foi reforçado com a publicação do Green Paper: Unlocking the Potential of Cultural and Creative Industries, de 2010 ("Libertando o potencial das indústrias culturais e criativas", em português), cujo objetivo foi realçar a importância destas indústrias para tornar a Europa mais competitiva, incentivando os Estados-Membros a investir e a implementar políticas públicas para o setor cultural e criativo. Mesmo que seja possível encontrar reflexões com abordagens econômicas sobre a cultura em obras paradigmáticas da economia, a verdade é que alguns dos economistas clássicos mais destacados (Adam Smith, David Ricardo e Alfred Marshall, por exemplo) não atribuíram, nos seus trabalhos, grande importância ao setor cultural como atividade econômica. Aliás, esses autores consideravam as artes atividades economicamente improdutivas, ou seja: o trabalho aplicado na execução das obras e os custos relativos à sua aquisição eram considerados um desperdício de recursos que poderiam ser aplicados em outros setores mais produtivos.

\section{Revista Intercom - O que identifica como a principal propriedade de uma indústria criativa?}

Faustino - O conceito de indústria criativa está agora bastante presente tanto no discurso acadêmico como no político. Embora o tema e o conceito tenham sido originalmente abordados por investigadores australianos, historicamente tem as suas raízes nas políticas nos governos New Labour de Tony Blair, entre o final dos anos 1990 e 2000. Essas políticas para as indústrias criativas foram, por sua vez, influenciadas por estratégias culturais de renovação urbana em algumas das maiores cidades do Reino Unido como Manchester, Sheffield e Glasgow, e pelas estratégias econômicas de políticas culturais do governo 
australiano como parte do programa "Nação Criativa”, de 1994. Nos anos 2000 ocorre um processo significativo de difusão das políticas para as indústrias criativas, com o desenvolvimento dessas políticas em cidades europeias. A dimensão urbana das indústrias criativas foi particularmente significativa na Ásia, onde houve importantes iniciativas para ligar as indústrias criativas às estratégias de cidades globais em cidades como Seul, Cingapura, Bangkok e Hong Kong. As indústrias criativas têm as suas raízes no discurso político e não no acadêmico. Significa que tem havido alguma contestação e até mesmo alguma confusão conceitual entre os investigadores que trabalham com o conceito. Termos como "indústrias criativas”, “indústrias culturais”, “indústrias culturais e criativas”, “indústrias de copyright”, “indústrias cognitivo-culturais” e "indústrias de produtos culturais” têm sido usados repetidas vezes. O campo atravessa a divisão entre as humanidades e as ciências sociais, significando que as tensões entre as tradicionais investigações 'críticas' e 'administrativas' também se desenrolam em debates acadêmicos. As indústrias criativas têm fornecido pontes importantes entre o conhecimento das ciências humanas e das ciências sociais. Enquanto o foco nas indústrias implica um foco na economia e nos negócios, constatou-se que as correntes dominantes da teoria econômica, como a microeconomia neoclássica, não estão bem preparadas para compreender os media digitais e a cultura, por exemplo. As indústrias criativas estão associadas a um ressurgimento do interesse na criatividade e nas cidades e no importante papel desempenhado pelas perspectivas geográficas em debates acadêmicos e políticos. Em contraste com os prognósticos iniciais, de que a proliferação global da Internet e das tecnologias de mídia digital iria reduzir a importância da dimensão local, tem havido uma procura representativa de artistas, empresários, investidores, decisores políticos, jornalistas, animadores culturais, entre muitos outros, para descobrir a fonte da criatividade e a sua relação com os lugares. Nesse sentido, a geografia nos fornece uma série de conceitos importantes por meio dos quais a dinâmica econômica das cidades e as suas intersecções com a cultura podem ser compreendidas. O primeiro enquadramento usado para entender a relação entre as indústrias criativas e as cidades foi o dos clusters. Como mencionei antes, o interesse pelos clusters entre economistas e geógrafos data do trabalho de Alfred Marshall sobre distritos industriais no final do século XIX, onde ele identificou as externalidades positivas que podem surgir a partir de um agrupamento de empresas e indústrias relacionadas entre si num determinado local. O conceito de cluster reapareceu na década de 1990, no trabalho do teórico em gestão empresarial Michael Porter, que argumentou que as fontes dinâmicas e sustentáveis da vantagem competitiva derivavam menos da redução de custos e eficiências de produção e mais de elementos de um lugar que promovem o crescimento da produtividade e da inovação ao longo do tempo. No mundo globalizado, a concorrência entre países começa a perder importância, dando lugar à concorrência entre as cidades. As regiões com futuro serão aquelas capazes de oferecer produtos e serviços criativos diferentes ao mercado mundial, incluindo o mercado da língua portuguesa, por exemplo, atraindo e retendo talento e capital para um desenvolvimento 
econômico sustentável. Trata-se de um setor que tem papel cada vez mais relevante na criação de emprego e de riqueza e na promoção da qualidade de vida da população, em especial a urbana. Isso contribui, sem dúvida, para a competitividade imprescindível ao crescimento econômico sustentável e para a coesão nas vertentes econômica, social e territorial. O setor cultural e criativo abrange quatro grandes componentes que se articulam de uma forma dinâmica e complementar: a cultura e a economia, por um lado, e a economia e a criatividade, por outro.

Revista Intercom - Em linhas gerais, o que mais se destaca nas investigações sobre pluralismo nos meios de comunicação?

Faustino - O pluralismo constitui um princípio e um fator crítico do sucesso de qualquer democracia. Nesse contexto, não será difícil justificar a relevância do tema e o potencial papel das entidades reguladoras como parceiras na promoção do pluralismo e da sustentabilidade das sociedades. Normalmente, é possível distinguir vários regimes de regulação, que cito a seguir. Em primeiro lugar, as restrições à propriedade - caso da propriedade de empresas de um único meio (por meio da definição de limite superior da porcentagem detida por um proprietário da empresa, de forma a induzir uma estrutura de propriedade mais fragmentada); a propriedade de vários meios (via estabelecimento de limites intraindustriais de acumulação de propriedade na imprensa e licenças de transmissão de rádio ou TV, por exemplo); no caso de proprietários estrangeiros, para limitar a participação de empresas do exterior no capital de empresas locais, que é o caso do Brasil, onde o capital estrangeiro nas empresas de mídia não pode ser superior a 30\%; e proibições absolutas (partidos políticos e departamentos ou instituições em nível central ou regional: organismos públicos da administração direta, indireta, autônoma, central, regional ou local). Em segundo lugar, no que se refere à limitação do número de licenças, como por exemplo, a proibição de um grupo deter mais de uma licença nacional de radiodifusão no Reino Unido - o mesmo acontece em Portugal com as atribuições de licenças de televisão aberta (freeto-air). Em terceiro lugar, em relação às limitações das cotas de mercado, ou limitação da concentração conforme medida pelas cotas de mercado calculadas em termos de audiência ou volume de negócios. Este aspecto pode estar definido em leis sobre a concentração da propriedade (as leis setoriais preveem limites, caso das leis para o rádio, para a TV etc.). Finalmente, em quarto lugar, a questão das limitações de mensagens publicitárias, em base horária ou diária ou em função da natureza da propriedade da empresa - existe a tendência de abolir algum tipo de publicidade nos canais de televisão pública, por exemplo, embora na verdade todo canal de TV tenha limites publicitários por hora. Como vê, temas de regulação podem se dividir em questões econômicas, relacionadas com a concorrência, e questões não econômicas, associadas a políticas públicas. Estas últimas incluem questões de conteúdos (promoção de serviços públicos ou mensagens culturais, proteção de menores, controle da 
publicidade) e também de acesso. Observa-se ainda uma mudança da noção de regulação para autorregulação, que resulta, em parte, do aumento da complexidade tecnológica no setor de transmissão. Na prática, isso envolve o estabelecimento de diretivas gerais por autoridades de alto nível, que são posteriormente seguidas por entidades independentes de outros níveis. A regulação da mídia não é, em parte alguma do mundo (em Portugal tem sido motivo de polêmicas que acabam por ser normais devido à natureza da atividade), um tema propriamente “pacífico” e tem gerado muitas controvérsias entre reguladores, regulados e governos. Justifica-se, em parte, que o setor de mídia seja alvo de uma regulação mais intensa, o que significa observar com algum cuidado as mensagens e os conteúdos difundidos, especialmente o que se comunica e como se comunica à audiência. Neste contexto, o papel da regulação deve prestar especial atenção à programação dirigida a grupos minoritários. Uma vez que o controle pode ajudar a promover a diversidade, percebe-se que a regulação da propriedade dos media é essencial, pois se houver um controle de quem detém produtos de mídia (sobretudo quando há concentração excessiva e impactos negativos decorrentes de uma posição dominante), isso terá automaticamente repercussões na programação de cada meio e também no que diz respeito à respectiva participação dos cidadãos.

Revista Intercom - Como seria possível então abordar questões de pluralidade e de diversidade na mídia?

Faustino - A regulação pode ajudar a sensibilizar os operadores de mídia na promoção da diversidade de conteúdo, incluindo a existência de programas destinados a público mais específico. Em todo caso, é de sublinhar que se é verdade que, por uma questão de conduta e responsabilidade social, todas as empresas de mídia devem prestar atenção aos impactos negativos das suas mensagens, essa responsabilidade deverá ser maior nos operadores públicos de mídia, sobretudo porque não estão tão dependentes do mercado publicitário. A regulação deverá ter em conta algumas lógicas e contingências de mercado que afetam de forma diferente a conduta, as estratégias de programação e as práticas de gestão das empresas de mídia conforme sejam constituídas por capitais públicos ou privados. Garantir o pluralismo tem o seu preço, que pode ser justificado se a regulação contribuir para a sustentabilidade - e também das empresas - e o desenvolvimento do processo democrático. A regulação (em articulação com autorregulação e corregulação) é cada vez mais necessária, desde que seja identificado um modelo adequado às características do mercado em que operam os regulados e corresponda às especificidades de cada Estado e respectivas exigências de cidadania e dignidade humana. No Brasil, o tema da regulação deveria ser levado mais a sério pelos governos, com a criação de uma entidade especializada para criar novas competências e reagrupar algumas que estão dispersas. Importa destacar que uma entidade reguladora não pode ser confundida com uma entidade "controladora”, como acontece em alguns países, incluindo o continente sul-americano, em que governos, sob 
a ideia errada do conceito de regulação, acabam por controlar os meios de comunicação e reduzir substancialmente o pluralismo. Uma regulação inteligente e plural implica um esforço em vários níveis: proteger o cidadão de conteúdos impróprios, regular o que pode ser monitorado, promover a diversidade de vozes no mercado, compreender a função econômica das empresas, promover o diálogo entre regulador e regulado - ou seja, dar prioridade à regulação conjunta (corregulação). Só quando isso não funcionar é que deve assumir uma função mais robusta, mas isso também significa compreender bem os impactos das decisões tomadas. Apesar da concentração da propriedade (que é muito elevada no Brasil) continuar a ser um dos âmbitos importantes da regulação, uma das principais preocupações hoje é promover a transparência da propriedade, uma vez que sabendo quem são os sóciosproprietários também conseguimos perceber melhor o contexto das suas práticas, incluindo compreender o significado dos conteúdos.

Revista Intercom - Ao longo dos anos, e no desempenho de funções variadas [secretáriogeral da Confederação Portuguesa dos Meios de Comunicação Social, vice-presidente da Associação Portuguesa de Imprensa - API; presidente do Observatório da Comunicação - Obercom; e administrador do Centro Protocolar de Formação de Jornalistas - Cenjor], você de alguma forma direcionou o seu olhar para estudos que consideram os meios nacionais e/ou regionais?

Faustino - Sim. Entendo que a revolução digital está transformando os negócios dos media e acelerando os processos de convergência e de globalização. Simultaneamente, observase alguma desregulação das indústrias nacionais de mídia. Em paralelo, assistimos a um crescimento da importância da mídia como negócio, o que tem favorecido a integração de gestores profissionais com MBAs. Tais mudanças, no seu conjunto, reforçaram o interesse no ensino e na investigação focada nos problemas específicos da indústria, particularmente na perspectiva da economia e da gestão empresarial dessas organizações. Com isso, cresce o número de profissionais que se dedicam a tarefas de direção e gestão de empresas e produtos de mídia. Por outro lado, é cada vez mais frequente as empresas de mídia concorrerem em outros mercados, lançar produtos, implementarem tecnologias mais avançadas. Para compreender, identificar e responder melhor às profundas alterações do setor é necessário refletir sobre os domínios da economia e gestão empresarial aplicados à indústria da comunicação, incluindo a compreensão da vertente criativa/intelectual dos profissionais do jornalismo. Tendo trabalhado vários anos em meios de comunicação e em outras atividades políticas, associativas e formativas ligadas ao setor, é natural que isso tenha influenciado a minha forma de observar a atividade numa dimensão mais alargada, uma vez que as organizações não são 'ilhas’ e para compreender suas práticas é necessário perceber o contexto em que operam, em especial: como está organizado e estruturado o mercado, quais são as práticas e condutas de gestão e quais os resultados obtidos. As experiências 
profissionais relacionadas à indústria de mídia guiaram meus interesses e motivações de estudo, também mais alargados, na tentativa de compreender e contextualizar as práticas de gestão e modelos de negócio, observadas as dinâmicas de mercado, as políticas públicas vigentes e as competências formativas existentes ou emergentes. Isso tem contribuído para sistematizar alguns conhecimentos enquanto investigador e docente em estudos de mídia e indústrias criativas, incluindo os meios regionais e locais que me parecem, em muitos casos, terem condições de enfrentar melhor o futuro que os meios 'nacionais', por terem impacto concreto no cotidiano das pessoas e a capacidade de reforçar uma relação de identidade e comunicação mais próxima entre emissor e receptor (jornais e leitores, por exemplo). A globalização também gera um movimento simultâneo de refluxo: a localização. À medida que a informação se torna mais global, há necessidade de a sociedade redescobrir e reforçar sua identidade e raízes. Por isso creio que a investigação sobre o papel da mídia regional e local necessita ser reforçada. No caso português, é interessante observar que a circulação dos jornais regionais e locais, comparada com os 'nacionais', estão a resistir melhor, perdendo menos leitores e circulação que os nacionais. Nos últimos anos tenho realizado investigações na área da mídia e indústrias criativas, mas tenho planos de retomar a investigação sobre meios regionais e locais porque existem dinâmicas novas que precisam ser compreendidas, incluindo a perspectiva da sustentabilidade empresarial.

Revista Intercom - Você também é sócio e presidente não executivo de uma editora em Lisboa (Media XXI) com foco no campo da economia de mídia. Quem são os autores que melhor identificam a linha da editora? De onde vem o interesse pelo universo brasileiro da comunicação?

Faustino - A Media XXI é uma marca da Formalpress, fundada em junho de 2003 e especializada nas áreas da sociedade da informação, gestão de mídia, marketing e indústrias criativas. Com o conhecimento adquirido em consultoria, investigação, formação e edição, a Formalpress criou a MediaXXI para se posicionar no mercado nacional e internacional. Atualmente, o seu campo de atuação se distribui em seis domínios para além da edição e produção de conteúdos, que é sua atividade principal. A Formalpress/Media XXI colabora com diversas instituições, incluindo centros de investigação e universidades, no desenvolvimento de pesquisa predominantemente aplicada. Trata-se, portanto, de empresa com forte conexão com a academia, parceira da comunicação científica para a publicação, transferência e disseminação do conhecimento. Como orientação estratégica - e também porque a Formalpress/Media XXI recebeu um prêmio/incentivo do Estado português (de coparticipação em alguns investimentos nos próximos dois anos) para dinamizar sua presença no exterior - estamos apostando na internacionalização. O Brasil assume uma atenção prioritária (já temos operações e colaboradores a partir de São Paulo) pela sua dimensão e pela afinidade cultural e linguística e também porque tem uma comunidade científica muito 
dinâmica, com trabalhos relevantes que necessitam ser divulgados em nível internacional, em especial no mercado anglo-saxônico. Estamos colaborando com universidades e autores brasileiros nesse sentido. Adicionalmente, existem relações emocionais: o Brasil é meu segundo país, se é que posso fazer esta apropriação abusiva... É preciso considerar também que a migração para o digital facilita processos de internacionalização na área da edição e indústrias criativas. São transformações que suscitam alterações nas dinâmicas do mercado, nos hábitos de consumo influenciados pelo aparecimento de gadgets tecnológicos. Este cenário determina a prioridade dos investimentos nos vários níveis da cadeia de valor da edição: processo produtivo e editorial; transformação e desmaterialização do produto; comercialização em formatos digitais; marketing e comunicação internacional dos produtos e serviços; gestão e relação com clientes. Trata-se de uma atividade com crescente importância da base tecnológica que requer acordos com parceiros em nível internacional, especialmente no Brasil. Hoje é possível produzir livros em condições de preço muito favoráveis ao leitor, sem necessidade de imprimir grandes quantidades porque os livros podem ficar à venda, disponíveis por encomenda - o impresso chega em um tempo relativamente curto à casa do leitor ou de imediato via versão digital. No Brasil a distribuição e venda é feita pela Disal, que também possui livrarias. Ao se posicionar no mercado editorial das ciências da comunicação e das indústrias criativas, a Media XXI contribui para a valorização do capital intelectual, científico e técnico dos autores e centros de investigação e para gerar valor econômico e social para a sociedade, particularmente a comunidade científica. Atualmente a Media XXI é uma das editoras que mais publicam livros na área das ciências da comunicação porque faz isso em vários idiomas, com predomínio do português, espanhol e inglês. Para tanto, conta com uma rede de colaboradores constituída por professores, pesquisadores e especialistas que ajudam a identificar autores e avaliar conteúdos. Parte desta rede também colaborou no lançamento da revista científica Journal of Creative Industries and Cultural Studies - JOCIS, formando um comitê editorial internacional que ajuda a qualificar o trabalho.

Revista Intercom - Assim como no jornalismo, os recursos da tecnologia são os maiores facilitadores desse processo de produção editorial?

Faustino - As tecnologias estão a potenciar a convergência de suportes e de conhecimentos - informação e comunicação fazem cada vez mais parte da mesma cadeia de valor e visão de uma indústria tendencialmente integrada nos seus gêneros. Paradoxalmente, isso reforça a necessidade de conhecer e estudar para diferenciar o papel de cada campo na produção de conteúdos. As tecnologias vieram igualmente relevar a necessidade de organizar e gerir a informação, criando soluções (ferramentas e softwares) que podem melhorar sua utilização nas organizações. Nós, acadêmicos, conseguimos verificar essa situação no dia a dia, ou seja, não basta sabermos escrever bons artigos, mas adaptarmos o conteúdo às revistas ou 
publicações pertinentes de acordo com regras bem definidas. Na prática, temos de saber produzir conteúdos, mas também saber gerir a organização e a disseminação da informação. O mesmo acontece com a mídia: na produção de conteúdos, a capacidade de saber editar, selecionar e adequar a suportes idênticos requer competências de gestão da informação, que se assenta na capacidade de criar conteúdos (criativa) e na de selecionar (organizativa) e de disseminar (tecnológica) junto a públicos com afinidade e interesse por esses conteúdos. Em simultâneo com a maior facilidade, e até banalização, na criação de conteúdos, volta a ganhar importância saber editar conteúdos, circunstância que exige competência apurada no nível da gestão da informação. Por outro lado, as mudanças tecnológicas, o aparecimento de novos suportes e alteração do gosto dos consumidores afeta as formas de criação, produção e disseminação das práticas jornalísticas, bem como as estratégias de gestão e organização das empresas de mídia. Desde a década de 1920 até o começo do século XXI, a comunicação incentiva o desenvolvimento de correntes de investigação que tendem a especializar-se. Há várias décadas, a informação (jornalística e não só) se converteu em um fator competitivo da indústria de mídia, ou seja: o sucesso da organização jornalística depende não só da capacidade de criar conteúdos que correspondam às necessidades dos consumidores, mas também da capacidade de gerir e selecionar contextos e significados associados às mensagens. Adicionalmente, depende da utilização de sistemas de informação que permitam otimizar e disseminar de forma eficaz, eficiente e sustentável a produção de conteúdos que podem se tornar informação relevante ou não para os consumidores.

\section{Sonia Virginia Moreira}

Possui graduação em Comunicação Social - Jornalismo (Universidade Gama Filho), mestrado em Jornalismo (University of Colorado) e doutorado em Ciências da Comunicação (Universidade de São Paulo). Professora associada da Faculdade de Comunicação Social da Universidade do Estado do Rio de Janeiro, integra o corpo docente do Departamento de Jornalismo e do Programa de Pós-graduação em Comunicação Social. Membro permanente do conselho curador da Sociedade Brasileira de Estudos Interdisciplinares da Comunicação - Intercom; membro do conselho científico da SBPJor - Associação Brasileira de Pesquisadores em Jornalismo. Pesquisadora sênior de duas redes internacionais de pesquisa: o Worlds of Journalism Study (LMU Munich) e o International Media Concentration Research Project (University of Columbia). Lidera o Grupo de Pesquisa Geografias da Comunicação (CNPq). Tem experiência na área de Comunicação, com ênfase em jornalismo e radiodifusão, e produção nos seguintes temas: estudos de rádio, estudos de jornalismo, comunicação internacional, economia de mídia e indústria de mídia. E-mail: soniavm@gmail.com.

Recebido em: 20.08.2017

Aceito em: 26.10.2017 